\title{
REVIEW
}

\section{New light on Myc and Myb. Part II. Myb}

\author{
Bernhard Lüscher and Robert N. Eisenman
}

Division of Basic Sciences, Fred Hutchinson Cancer Research Center, Seattle, Washington 98104 USA

One of the critical steps in the adjustment of cells to altered environmental conditions is the transduction of signals, emanating either from outside or from within the cell, which result in altered gene expression. Transcription factors can function as the molecular switches that sense incoming signals and modulate the transcription of specific genes (Ptashne 1988; Herrlich and Ponta 1989; Mitchell and Tjian 1989). Some of these modulatory transcription factors are likely to be involved in regulation of growth control genes. Deregulation of these factors may interfere with and disturb normal regulated cell growth, possibly leading to neoplasia. In this sense, it is not surprising that all of the nuclear oncoproteins with known biochemical function have turned out to be transcription factors. Myb is no exception. Work from a number of laboratories has recently brought the molecular function of the nuclear oncoprotein Myb into focus. Both in vitro and in vivo experiments provide strong evidence that Myb is a sequence-specific DNA-binding protein with the ability to trans-activate promoters containing its binding site (Biedenkapp et al. 1988, Klempnauer et al. 1989; Nishina et al. 1989; Weston and Bishop 1989; Lane et al. 1990). The view of Myb as a transcriptional regulator has been reinforced by analysis of the structure of the protein with its distinct DNAbinding domain, trans-activating domain, and positive and negative regulatory regions. In what follows we shall discuss some of the recent evidence supporting these ideas (for a recent in-depth review on the biology and expression of Myb, see Shen-Ong 1990).

\section{Myb: a regulator of cell growth and differentiation}

The work linking Myb to regulation of cell growth and differentiation has, to a large extent, paralleled similar studies on Myc. However, whereas Myc is expressed in many different tissues, Myb expression appears to be largely restricted to the hematopoietic system. However, there are some exceptions: c-myb expression has been detected in certain nonhematopoietic tumor cell lines (Thiele et al. 1988) and, in addition, there has been a report describing the presence of c-myb mRNA in fibroblasts (Thompson et al. 1986; although no Myb protein has been found in either primary fibroblasts or in established fibroblast cell lines; B. Lüscher, unpubl.). Early experiments had demonstrated that in hematopoietic cells of more mature phenotype, myb mRNA levels were relatively low compared with immature cells (Gonda et al. 1982; Westin et al. 1982; Coll et al. 1983; Duprey and Boettiger 1985). This down-regulation

Part 1 of this review appeared in the previous issue of the journal (December, number 12a). of myb mRNA during cellular differentiation has been studied most extensively in myeloid erythroleukemia (MEL) cells, which can be induced to differentiate by various agents. During MEL cell differentiation, the levels of $c-m y b$ mRNA decrease $>10$-fold during the first several hours but recover to almost control amounts within $24 \mathrm{hr}$. This transient increase is followed by a slow decrease in c-myb mRNA levels between days 2 and 5 of differentiation (Kirsch et al. 1986; Clarke et al. 1988). Importantly, the introduction of vectors expressing high constitutive levels of c-myb results in inhibition of differentiation, strongly suggesting that the down-regulation of myb may be critical for differentiation to proceed (Clarke et al. 1988; McMahon et al. 1988; Todokoro et al. 1988; McClinton et al. 1990). Forced expression of exogenous c-myb does not affect the early, but inhibits the late, down-regulation of endogenous c-myb (Clarke et al. 1988). Furthermore, Myb only affects MEL cell differentiation when it is expressed 3 days following addition of inducer, arguing for a critical role of the late down-regulation of c-myb mRNA in differentiation (McClinton et al. 1990). Recently, an alternatively spliced form of myb whose expression appears to accelerate differentiation has been identified (Weber et al. 1990; see below).

Myb also plays a role in, and has a stimulatory effect on, cell growth. When hematopoietic colony-forming cells are exposed to myb antisense oligonucleotides, a decrease in the number of cells in individual colonies was observed. These cells were indistinguishable from control cells in terms of their differentiation /Gewirtz and Calabretta 1988), suggesting that decreased Myb levels accelerate differentiation by allowing it to occur within fewer cell divisions. Furthermore, elevated myb expression can transiently increase the proliferation rate of hematopoietic cells (Gonda et al. 1989b). These data suggest a critcal role for Myb in cell proliferation and differentiation.

\section{A widespread group of genes with a related DNA-binding motif}

Sequence comparison of Myb and Myb-related proteins from various species reveals a highly conserved region close to the amino terminus consisting of three imperfect repeats (R1, R2, R3) of 51-52 amino acids in c-Myb (Fig. 1). Two of these domains, R2 and R3, in both mouse and chicken $\mathrm{Myb}$, are responsible for specific DNA binding (see below). The 103 residues comprising R2 and $\mathrm{R} 3$ are essentially identical in human, chicken, and murine $\mathrm{Myb}$, while the remaining portions of these proteins are somewhat less conserved. In the several Myb-related 


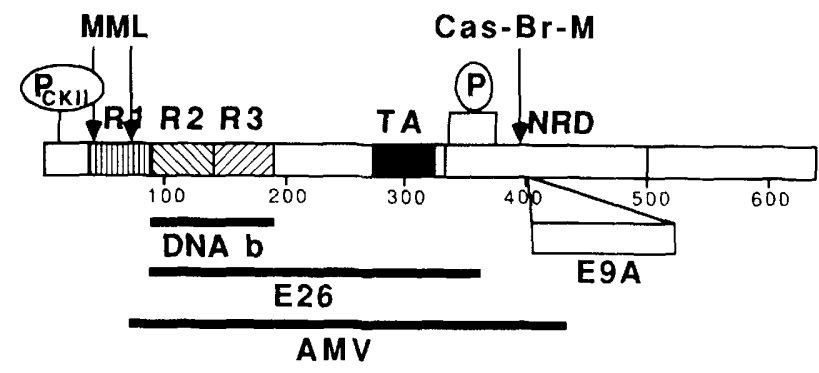

Figure 1. Schematic representation of the c-Myb protein [639 amino acids (murine), $75 \mathrm{kD}$ ]. The following structural features are indicated: (R1 R2 R3) 51- to 52-amino-acid repeats; (TA) trans-activation domain; (NRD) negative regulatory domain, as defined in murine Myb (Sakura et al. 1989); $\left(\mathrm{P}_{\mathrm{CKII}}\right)$ casein kinase II phosphorylation site; $\{\mathrm{P}\}$ region containing several phosphorylation sites (Bading et al. 1989; W. Boyle, pers. comm.); (DNA b) DNA-binding domain; (E9A) alternatively spliced exon giving rise to a mRNA coding for a 760 -amino-acid protein of $85 \mathrm{kD}$; (E26 and AMV) Myb homology region in the two avian retroviruses E26 and AMV, respectively; (MML) M-MuLV proviral integrations in mouse myeloid leukemias; (Cas- $\mathrm{Br}-\mathrm{M}$ ) proviral integrations of Lake Cassitas mouse virus in two myeloid cell lines. (For a detailed description of these elements and references, see text.)

proteins described below, the $\mathrm{R} 2 / \mathrm{R} 3$ regions also show a high degree of homology with $\mathrm{c}-\mathrm{Myb}$, while the remaining parts of the protein are distinctly different.

The Myb DNA-binding domain bears little resemblance to the known DNA-binding domains of transcription factors, which possess zinc fingers, basic region/leucine zipper, and basic region/helix-loop-helix (H-L-H) domains (for review, see Johnson and McKnight 1989; Mitchell and Tjian 1989). Despite the lack of an obvious DNA-binding motif, several structural features of the Myb repeats have been noted. It has been pointed out that the potential to form three $\alpha$-helical segments within each of the repeats resembles the H-L-H structure into which the homeo domain of the Antennapedia protein folds (Frampton et al. 1989, and see references therein). The $\mathrm{R} 2 / \mathrm{R} 3$ domain contains a relatively high percentage of basic amino acids (23\%), reminiscent of the extensive and highly basic DNA-binding domain of the transcription-replication factor CTF/NF-1, which is also extensive and highly basic (Mitchell and Tjian 1989). Furthermore, within all three repeats, the presence of three conserved tryptophan residues spaced by 18 or 19 amino acids has been noted (Anton and Frampton 1988). The occurrence of such a rare amino acid spaced in this manner hints at the possibility of a unique structure. Therefore, the Myb DNA-binding domain is an evolutionarily conserved element that may represent a novel type of specific DNA interaction motif. Interestingly, a similar type of tryptophan spacing has been idenetified in ets-family proteins (Karim et al. 1990).

To date, three Myb homologs (human, mouse, and chicken) have been identified that possess a high degree of identity throughout the protein /Gonda et al. 1985; Gerondakis and Bishop 1986; Majello et al. 1986; Rosson and Reddy 1986). The chicken c-myb gene is the cellular homolog of the two virally transduced myb genes $/ \mathrm{v}$ $m y b)$ in avian myeloblastosis virus (AMV) and E26 (Fig. 1). These are expressed as fusion proteins (p48gag-myb in AMV and p1358as-myb-ets in E26) containing amino- and carboxy-terminal truncations with respect to $\mathrm{c}-\mathrm{Myb}$ (Bister et al. 1982; Klempnauer et al. 1982, 1983; Rushlow et al. 1982; Rossen et al. 1987). In addition, several Myb-related proteins and cDNAs have been described from human, Drosophila, yeast, and Zea mays, with the DNA-binding domain being the most conserved region (Paz-Ares et al. 1987; Peters et al. 1987; Nomura et al. 1988; Tice-Baldwin et al. 1989/. Two cDNAs with limited Myb homology have been cloned from a human T-cell cDNA library (A-myb and B-myb, respectively; Nomura et al. 1988). These two members of a growing class of myb-related genes may be expressed more widely than c-myb, which is primarily restricted to hematopoietic tissue (Gonda et al. 1982; Westin et al. 1982; Coll et al. 1983). Whereas A-myb mRNA levels were high in cell lines of kidney, colon, or lymphoid origin, no specific transcripts were detected in neuroblastoma or stomach carcinomas. In contrast, B-myb mRNA was found in all of the cell lines tested (Nomura et al. 1988). Recently, it has been shown that B-Myb is a transcriptional activator and has a DNAbinding specificity similar to c-Myb (Mizuguchi et al. 1990).

The most distant relative of $\mathrm{c}-\mathrm{Myb}$ is the BASl gene of Saccharomyces cerevisiae, which encodes a DNAbinding protein involved in the regulation of the HIS4 gene. Sequence analysis revealed homology of BASl with Myb in the DNA-binding domain (Tice-Baldwin et al. 1989|. BAS1, together with BAS2, is responsible for the basal expression of HIS4 and its induction in response to adenine starvation. Interestingly, the DNA sequence recognized by BASI very closely resembles a Myb response element (MRE; see below). Another Mybrelated protein is encoded by the $c 1$ locus in Zea mays, which appears to code for a regulatory protein required for tissue-specific pigmentation (Paz-Ares et al. 1987). Interestingly, $\mathrm{Cl}$ may function within the same pathway as the H-L-H protein Lc (Ludwig et al. 1989; see part I of this review). Thus, genes containing the Myb DNA-binding motif have been identified in a wide variety of different organisms. In all cases studied, the encoded proteins are involved in transcriptional regulation.

\section{The Myb DNA-binding motif recognizes a specific DNA sequence}

Although it has been known for quite some time that Myb binds nonspecifically to DNA, only very recently has a defined nucleotide sequence been shown to be recognized specifically by $\mathrm{Myb}\left(\mathrm{Py} \mathrm{AAC}^{\mathrm{G}} / \mathrm{T} \mathrm{G}\right.$; denoted here as MRE; Biedenkapp et al. 1988). The DNA-binding domain of Myb had initially been identified by assaying the nonspecific DNA-binding capacity of a series of deletion mutants (Klempnauer and Sippel 1987). These ex- 
periments, together with the fact that $\mathrm{v}-\mathrm{Myb}$ proteins do not contain $\mathrm{R} 1$ yet still can bind to an MRE, suggest that R2 and R3 are sufficient to confer DNA binding (Biedenkapp et al. 1988; Ness et al. 1989; Lüscher et al., 1990). This idea has been supported further by experiments in which deletion of either of these two repeats results in loss of DNA binding, suggesting that R2 and R3 function as a unit. Similarily, small deletions at the carboxyl terminus of R3 abolish MRE binding (Howe et al. 1990). These data clearly map the specific DNA-binding domain to R2 and R3.

\section{Myb is a trans-activator with positive and negative regulatory domains}

The MRE is not only recognized by Myb in vitro but also serves as a cis-acting element for Myb-specific trans-activation of promoters linked to reporter genes (Klempnauer et al. 1989; Sakura et al. 1989; Weston and Bishop 1989; Ibanez and Lipsick 1990|. The MRE can apparently function both $5^{\prime}$ and $3^{\prime}$ of a promoter, thus suggesting that an MRE is an "enhancer"-like site (Nishina et al. 1989). However, careful evaluation of the orientation and distance dependence of its effect still needs to be carried out.

Deletion and linker insertion analysis of $c-M y b$, as well as $\mathrm{V}-\mathrm{Myb}$, revealed a 50-residue trans-activation domain located carboxy-terminal to the DNA-binding domain (see Fig. 1; Sakura et al. 1989; Weston and Bishop 1989; Ibanez and Lipsick 1990; Lane et al. 1990). The trans-activator domain appears to be hydrophilic and slightly acidic, as expected in analogy to other trans-activator domains (for review, see Ptashne 1988). However, it is presently not clear if the acidity of the region or some higher-order structure is of importance. In favor of the latter interpretation is the finding that a small deletion of only 11 amino acids within the trans-activator domain, which has little effect on the overall charge of this region, abolishes $\mathrm{Myb}$ trans-activating activity (Weston and Bishop 1989).

Interestingly, a negative regulatory domain has also been defined in Myb downstream of the activator. Deletions in the carboxy-terminal half of the protein result in an increase up to 10 -fold in Myb-specific trans-activation activity, suggesting the presence of sequences that normally repress activation (Fig. 1; Sakura et al. 1989; Ibanez and Lipsick 1990; Kalkbrenner et al. 1990; Lane et al. 1990). Three linker insertion mutants (Lane et al. 1990) that up-regulate trans-activation of AMV-Myb are clustered at the carboxy-terminal end of exon E9 (also referred to as $\mathrm{vE6}$; residues $317-401$ in mouse c-Mybl, an interesting region that is altered by proviral integrations and normal splicing (see below; Shen-Ong et al. 1986; Weinstein et al. 1986, 1987; Rosson et al. 1987; Shen-Ong 1987) and contains an isoleucine and three leucine residues with a characteristic heptad spacing reminiscent of a leucine zipper motif (Biedenkapp et al. 1988; Landshulz et al. 1988). Whereas in human Myb the carboxy-terminal 140 amino acids appear to contain the major negative regulatory domain, this domain is confined to a more internal region in mouse Myb (amino acids 326-500; Sakura et al. 1989; Kalkbrenner et al. 1990). The existence of this negative regulatory domain in mammalian and avian Myb and its apparent sensitivity to mutations suggests an important function. It may bind a factor that influences interactions with positive-acting elements or MRE binding. However, aside from the rather weak putative zipper motif, there is no direct evidence that this region is involved in proteinprotein interactions. In addition, some evidence against Myb dimerization exists, at least based on experiments using in vitro-translated protein (Howe et al. 1990).

In addition to the carboxy-terminal regulatory regions described above, a major phosphorylation site has been mapped near the amino terminus (Fig. 1 ; Lüscher et al. 1990). Phosphorylation of this site (Ser-11 and Ser-12) by casein kinase II (CK II) down-modulates binding of immunoenriched Myb to an MRE in vitro. This amino-terminal region is frequently lost in oncogenically activated Myb proteins (see below), suggesting a possible regulatory role of this phosphorylation site. This is supported further by the finding that the activity of $\mathrm{CKII}$ is altered in response to various growth factors (see references in Lüscher et al. 1990). How these various domains might cooperate in the regulation of Myb function is unclear at present.

In all of the cases described above, the trans-activating activity of Myb depends on a DNA-binding domain and the corresponding cis element linked to a promoter. However, two sets of data suggest that Myb DNA binding and trans-activation may hold some surprises. First, the presence of four point mutations in the AMVMyb DNA-binding domain appear to alter the specificity of binding to the promoter of the Myb-inducible gene mim-1 (see below; Ness et al. 1989). Second, three linker insertion mutants in $\mathrm{R} 2$ of AMV-Myb have quite distinct properties when scored by MRE-promoter transactivation and transformation of chicken yolk sac and bone marrow cells (Lane et al. 1990). One of the linker insertion mutants (close to the amino terminus of R2) trans-activates an MRE reporter construct and transforms bone marrow cells as efficiently as wild-type AMV-Myb, but is inactive in the yolk sac transformation assay. The two other linker insertions result in loss of function. One possible explanation for these differences is that the mutations in AMV las compared to c-Myb) and the R2 mutation modify the DNA-binding specificity or affinity of Myb. This could result in differential gene expression if a spectrum of MREs existed with distinct affinities for Myb. Indeed, the Myb-activated mim-l gene promoter may provide an example of such a spectrum (see below).

Recent evidence suggests that Myb may be able to trans-activate certain promoters (e.g., human hsp 70) in the absense of its DNA-binding domain (Klempnauer et al. 1989/. At this point it is unclear how this may work mechanistically. One possible explanation may be that a factor binding within the hsp70 promoter is able to interact with Myb and "use" its activator domain to increase transcription from the hsp 70 promoter (see, e.g., 
Stern et al. 1989). Alternatively, nonbound Myb may sequester a repressor (possibly through its negative regulatory domain) of the hsp70 promoter. It will be of interest to determine whether other promoters can be trans-activated in a DNA-binding independent manner and if the endogenous hsp 70 promoter is responsive to truncated Myb in a similar fashion.

All of the findings referred to above are based on studies with various promoter-reporter gene constructs to monitor Myb activity. An important question is whether cellular genes that are regulated by Myb in vivo can be identified. Interesting work addressing this question has made use of the ts21 E26 virus, which has transduced both myb and ets and contains a temperature-sensitive point mutation located in the DNAbinding domain of Myb. This conditional mutant can be used to generate chicken myeloid cells, which at the permissive temperature have an immature myeloblast phenotype and at the nonpermissive temperature differentiate into macrophage-like cells (Ness et al. 1989). These cells can be de-differentiated by shifting them back to the permissive temperature, an effect that correlates with the reactivation of the DNA-binding activity of the p1358ag-myb-ets fusion protein of E26 (Moelling et al. 1985; Beug et al. 1987). Using a subtractive hybridiza. tion screening protocol, clones were identified that were strongly induced when the cells were shifted from the nonpermissive to the permissive temperature. One of these clones, dubbed mim-1, was shown to encode a 326-amino-acid protein, which contains two imperfect Cys-rich repeats and is secreted (Ness et al. 1989). These characteristics are reminiscent of growth factors, but at present no direct evidence as to the function of $\mathrm{mim}-1$ is available. The expression of mim-1 is high in promyelocytes and low in macrophages. If $\mathrm{mim}-1$ were a true Myb-responsive gene, one would expect to find an $\mathrm{MRE}(\mathrm{s})$ in the promoter region. Indeed, the mim-1 promoter contains three MREs, which by all criteria used can bind Myb, albeit with different affinities, and are the obligatory cis-elements for Myb-specific trans-activation. These results are an important milestone in establishing the function of Myb as a transcription factor.

\section{Oncogenic activation of $\mathbf{M y b}$}

The oncogenic potential of Myb appears to be limited to hematopoietic cells, Myb being the only known oncoprotein that does not transform fibroblasts. Having identified several functional domains, as described above, and knowing that all activated Myb proteins are truncated, is there some way to rationalize oncogenic activation in terms of the functional organization of Myb? On first principles one might argue that loss of the two negative regulatory domains, the carboxy-terminal trans-repressor and the amino-terminal phosphorylation site involved in regulating DNA binding, might result in a Myb protein with both full trans-activating and constitutive DNA-binding activity. This is precisely what has occurred during the formation of the two viral forms of Myb (Fig. 1). v-Myb proteins have lost at least part of both negative regulatory domains, resulting in a protein with increased trans-activating activity (Weston and Bishop 1989|. Any further deletions introduced into the AMV-Myb protein, with the exception of small carboxyterminal truncations, abolish transforming activity (Ibanez and Lipsick 1988). This suggests that AMV$\mathrm{v}$-Myb is very close to a minimal transforming unit. Interestingly, in E26 the oncogenic fusion protein p135 gas-myb-ets contains sequences related to Ets-1, which has been recently demonstrated to encode a transcription factor (Gunther et al. 1990) whose putative DNAbinding domain also contains the tryptophan spacing characteristic of the Myb R1-R3 region (Karim et al. 1990). Therefore, Ets sequences in p135 gag-myb-ets could be important in enhancing the binding and trans-activating capacity of Myb and vice versa.

Amino-terminal truncations are also generated by retroviral insertion in murine myeloid leukemias and chicken bursal lymphomas (Shen-Ong et al. 1984, 1986; Gonda et al. 1987; Kanter et al. 1988; Pizer and Humphries 1989; E. Humphries and W. Hayward, pers. comm.). Such truncations were found in $>30$ cell lines analyzed. These deletions remove the CK II phosphorylation site, which is potentially important in negatively regulating DNA binding (Lüscher et al. 1990). There are also examples of tumors where retroviral integrations produce truncations carboxy-terminal rather than amino-terminal to the DNA binding and the trans-activator domains, deleting at least part of the negative regulatory domain (Shen-Ong et al. 1986; Weinstein et al. 1986, 1987). In addition to the truncations, oncogenically activated myb expression is frequently deregulated by being transcribed under the control of a retroviral long terminal repeat. These findings suggest very strongly that to activate Myb oncogenically, constitutive expression as well as amino- and/or carboxy-terminal deletions are required. However, they do not prove it. Therefore, it will be important to define separately regions that generate a transforming myb gene.

Development of an in vitro transformation system in hematopoietic cells would allow a critical test of the importance of the different Myb alterations. Although such assays have been established for avian cells (Beug et al. 1979; Moscovici and Gazzolo 1982; Radke et al. 1982), a Myb transformation assay in mammalian hematopoietic cells has been less straightforward. Using mouse fetal liver cells as targets, it was shown that retroviral vectors expressing full-length or carboxy-terminally truncated mouse Myb were very rarely able to immortalize immature myelomonocytic cells (Gonda et al. $1989 \mathrm{a}, \mathrm{b})$. When the retroviral genomes and transcripts of such lines were analyzed, it was found that in all cases the provirus was rearranged and alternative splice sites were used. In the three cell lines derived from infection with carboxy-terminally truncated $\mathrm{Myb}$, rearrangement of the provirus led to an additional amino-terminal truncation of Myb. In further transfection experiments into fetal liver cells, this rearranged provirus increased the apparent life span of colony-forming cells, whereas fulllength Myb had no detectable activity in this assay. 
However, even with truncated Myb, growth factor-dependent cell lines could be established only rarely (Gonda et al. 1989b). In this system carboxy-terminal truncations have been suggested to represent the critical step in the activation of Myb, while the amino-terminal deletion may not contribute significantly to Myb activation ( $T$. Gonda, pers. comm.). In contrast, deletion of the amino-terminal as well as the carboxy-terminal domains of chicken Myb independently appear to be sufficient to activate the transforming potential (J. Lipsick and T. Graf, pers. comm.).

All of the available data indicate that truncations at both ends of Myb contribute to oncogenic activation of the protein. However, deletions at either end may be sufficient to generate an activated Myb whose transformation phenotype is dependent on the specific developmental stage, the cell environment, and the cell type.

\section{Alternative splicing in $\mathbf{M y b}$ affects a regulatory element}

Several recent reports have indicated that c-Myb may be regulated in part by alternative splicing (Rosson et al. 1987; Shen-Ong 1987; Dasgupta and Reddy 1989; ShenOng et al. 1990). A larger form of c-Myb (with an apparent molecular mass of 85,000 ) translated from an alternatively spliced mRNA, containing an extra exon (E9A) of $363 \mathrm{bp}$, has been described in mouse cells (Dudek and Reddy 1989; Ramsay et al. 1989; Shen-Ong et al. 1989|. This protein can be detected in both primary thymocytes as well as established cell lines. This exon is located between E9 and E10 (vE6 and vE7) and interrupts, as described above, the putative negative regulatory domain. Similar observations were made in human cells where alternatively spliced exons between E9 and E10 (E9A) and between E10 and E11 (E10A) were found. At this point the identity of the proteins potentially encoded by these alternatively spliced messages is unclear, as two reports are contradictory in regard to their coding capacity (Dasgupta and Reddy 1989; Shen-Ong et al. 1990). As yet, no functional differences have been attributable to the spliced forms. However, an alternatively spliced c-myb mRNA encoding an amino- and carboxyterminally truncated Myb has recently been shown to induce MEL cell differentiation. This protein appears to retain the DNA-binding domain and the nuclear localization signal but lacks the activation domain. Thus, it may act as a dominant negative form that binds DNA but does not activate gene transcription and therefore interferes with normal c-Myb function (Weber et al. 1990). It is intriguing that c-myb appears to generate alternative protein forms that differ in the structure of one or several of their regulatory domains. It will be important to evaluate further whether these forms differ functionally and whether their production is regulated.

\section{Outlook}

Perhaps the two most important questions regarding Myb function are (1) what Myb-regulated genes are involved in transformation and (2) how does Myb regulate both hematopoietic cell growth and differentiation? Since the mim-l protein does not have growth stimulatory activities on cells that are targets for Myb transformation and mim-1 is not expressed in AMV-transformed cells, it seems unlikely that mim-1 is involved in cell transformation (S. Ness and T. Graf, pers. comm.). As some of the cell lines, which have oncogenically activated Mybs, and all v-myb-transformed avian myeloid cell clones are still growth factor dependent, one may speculate that growth factor-encoding genes are not likely targets for Myb trans-activation. Obviously, this leaves many other possibilities, such as receptor genes, other transcription factors, or other oncogenes. The second question addresses a problem that may be restricted to hematopoietic cells. The production of large numbers of effector cells in the hematopoietic system is achieved by the ability of less differentiated cells to have limited self-renewal in addition to their capacity to mature and terminally differentiate. Myb has a growth stimulatory effect on myeloid colony-forming cells (Gonda et al. 1989b), suggesting that Myb-modulated genes are involved in regulatory aspects of the cell cycle. The importance of Myb in differentiation is supported by its down-regulation during differentiation /Gonda et al. 1982; Westin et al. 1982; Coll et al. 1983; Duprey and Boettiger 1985), its ability to block differentiation if constitutively expressed (Clarke et al. 1988; McMahon et al. 1988; Todokoro et al. 1988; McClinton et al. 1990), and its dedifferentiation effect on transformed myeloid cells (Beug et al. 1987; Ness et al. 1987). Therefore, Myb seems to regulate genes that are incompatible with cellular differentiation, or it may suppress the transcription of differentiation-promoting genes. How can this regulation be achieved? One interesting possibility is that Myb may interact with distinct MREs. This differential DNA binding could result in cell stage- or cell type-specific interactions with other cellular factors, e.g., through the trans-repressor domain. The challenge now will be to identify members belonging to these proposed classes of Myb-responsive genes and to understand how Myb is regulated to carry out its diverse functions.

\section{Acknowledgments}

We are deeply grateful to our many colleagues who provided advice, unpublished information, and preprints. We also thank J. Firzlaff, A. Lassar, M. Linial, P. Neiman, and P. Whyte for critical readings of the manuscript and J. Smith for secretarial assistance. Work cited from the authors' laboratory was funded by grants from the National Cancer Institute (CA20225 and CA28151) and from the American Cancer Society.

\section{References}

Anton, I.A. and J. Frampton. 1988. Tryptophans in myb proteins. Nature 336: 719.

Bading, H., C. Beutler, and D. Moelling. 1989. Mapping of a small phosphopeptide at the carboxyterminus of the viral myb protein by monoclonal antibodies. Oncogene 4: 33-38. 
Beug, H., A. von Kirchbach, G. Doderlein, J.-F. Conscience, and T. Graf. 1979. Chicken hematopoietic cells transformed by seven strains of defective avian leukemia viruses display three distinct phenotypes of differentiation. Cell 18: $375-$ 390.

Beug, H., P.A. Blundell, and T. Graf. 1987. Reversibility of differentiation and proliferative capacity in avian myelomonocytic cells transformed by tsE26 leukemia virus. Genes Dev. 1: $277-286$.

Biedenkapp, H., U. Borgemeyer, A. E. Sippel, and K.-H. Klempnauer. 1988. Viral myb oncogene encodes a sequence-specific DNA-binding activity. Nature 335: 835-837

Bister, K., M. Nunn, C. Moscovici, B. Perbal, M.A. Naluda, and P.H. Duesberg. 1982. Acute leukemia viruses E26 and avian myeloblastosis virus have related transformation-specific RNA sequences but different genetic structures, gene products and oncogenic properties. Proc. Natl. Acad. Sci. 79: $3677-3681$.

Clarke, M.F., J.F. Kukowska-Latallo, E. Westin, M. Smith, and E.W. Prochownik. 1988. Constitutive expression of a c-myb cDNA blocks friend murine erythroleukemia cell differentiation. Mol. Cell. Biol. 8: 884-892.

Coll, J., S. Saule, P. Martin, M.B. Raes, C. Lafrou, T. Graf, H. Beug, I.E. Simon, and D. Stehelin. 1983. The cellular oncogenes c-myc, c-myb, and c-erb are transcribed in defined types of avian hematopoietic cells. Exp. Cell Res. 149: 151162.

Dasgupta, P. and E.P. Reddy. 1989. Identification of alternately spliced transcripts for human c-myb: Molecular cloning and sequence analysis of human c-myb exon $9 \mathrm{~A}$ sequences. Oncogene 4: 1419--1423.

Dudek, H. and E.P. Reddy. 1989. Identification of two translational products for c-myb. Oncogene 4: 1061-1066.

Duprey, S.P. and D. Boettiger. 1985. Developmental regulation of c-myb in normal myeloid progenitor cells. Proc. Natl. Acad. Sci. 82: 6937-6941.

Frampton, J., A. Leutz, T.J. Gibson, and T. Graf. 1989. DNAbinding domain ancestory. Nature 342: 134.

Gerondakis, S. and I.M. Bishop. 1986. Structure of the protein encoded by the chicken proto-oncogene c-myb. Mol. Cell. Biol. 6: 3677-3684.

Gewirtz, A.M. and B. Calabretta. 1988. A c-myb antisense oligodeoxynucleotide inhibits normal human hematopoiesis in vitro. Science 242: 1303-1306.

Gonda, T.J., D.K. Shieness, and J.M. Bishop. 1982. Transcripts from the cellular homologs of retroviral oncogenes: Distribution among chicken tissues. Mol. Cell. Biol. 2: 617-624.

Gonda, T.J., N.M. Gough, A.R. Dunn, and I. de Blaquiere. 1985. Nucleotide sequence of cDNA clones of the murine myb proto-oncogene. EMBO /. 4: 2003-2008.

Gonda, T.J., S. Cory, P. Sobieszczuk, D. Holtzman, and J.M. Adams. 1987. Generation of altered transcripts by retroviral insertion within the c-myb gene in two murine monocytic leukemias. I. Virol. 61: 2754-2763.

Gonda, T.J., R.G. Ramsay, and G.R. Johnson. 1989a. Murine myeloid cell lines derived by in vitro infection with recombinant $c-m y b$ retroviruses express $m y b$ from rearranged vector proviruses. $E M B O$ /. 8: 1767-1775.

Gonda, T.J., C. Buckmaster, and R.G. Ramsay. 1989b. Activation of c-myb by carboxy-terminal truncation: Relationship to transformation of murine haemopoietic cells in vitro. $E M B O$ /. 8: $1777-1783$.

Gunther, C.V., J.A. Nye, R.S. Bryner, and B.J. Graves. 1990. Sequence-specific DNA binding of the proto-oncoprotein ets-1 defines a transcriptional activator sequence within the long terminal repeat of the Moloney murine sarcoma virus. Genes Dev. 4: 667-679.

Herrlich, P. and H. Ponta. 1989. Nuclear oncogenes convert extracellular stimuli into changes in the genetic program. Trends Genet. 5: 112-116.

Howe, K.M., C.F.L. Reakes, and R.J. Watson. 1990. Characterization of the sequence-specific interaction of mouse c-myb protein with DNA. EMBO /. 9: 161-169.

Ibanez, C.E. and J.S. Lipsick. 1988. Structural and functional domains of the myb oncogene: Requirements for nuclear transport, myeloid transformation and colony formation. 7 . Virol. 62: 1981-1988.

1990. Trans-activation of gene expression by v-myb. Mol. Cell. Biol. 10: 2285-2293

Johnson, P.F. and S.L. McKnight. 1989. Eukaryotic transcriptional regulatory proteins. Annu. Rev. Biochem. 58: 799839

Kalkbrenner, F., S.D. Guehmann, and K. Moelling. 1990. Transcriptional activation by human c-myb and $\mathrm{v}$-myb genes. Oncogene 5: 657-661

Kanter, M.R., R.E. Smith, and W.S. Hayward. 1988. Rapid induction of B-cell lymphomas: Insertional activation of c-myb by avian leukosis virus. I. Virol. 62: 1423-1432.

Karim, F.D., L.D. Urness, C.S. Thummel, M.J. Klemsz, S.R. McKercher, A. Celada, C. Van Beveren, R.A. Maki, C.V Gunther, J.A.Nye, and B.J. Graves. 1990. The ETS-domain: A new DNA-binding motif that recognizes a purine-rich core DNA sequence. Genes Dev. 4: 1451-1453.

Kirsch, I.R., V. Bertness, J. Silver, and G.F. Hollis. 1986. Regulated expression of the $c-m y b$ and $c-m y c$ oncogenes during erythroid differentiation. J. Cell. Biochem. 32: 11-21.

Klempnauer, K.H. and A.E. Sippel. 1987. The highly conserved amino-terminal region of the protein encoded by the $\mathrm{v}-m y b$ oncogene functions as a DNA-binding domain. EMBO $/$. 6: $2719-2725$.

Klempnauer, K.H., T.J. Gonda, and J.M. Bishop. 1982. Nucleotide sequence of the retroviral leukemia gene $\mathrm{v}$-myb and its cellular progenitor c-myb: The architecture of a transduced oncogene. Cell 31: 453-463.

Klempnauer, K.-H., G. Ramsay, I.M. Bishop, M.G. Moscovici, C. Moscovici, J.P. McGrath, and A.D. Levinson. 1983. The product of the retroviral transforming gene $v$-myb is a truncated version of the protein encoded by the cellular oncogene c-myb. Cell 33: 345-355.

Klempnauer. K.-H., H. Arnold, and H. Biedenkapp. 1989. Activation of transcription by v-myb: Evidence for two different mechanisms. Genes Dev. 3: 1582-1589.

Landschulz, W.H., P.F. Johnson, and S.L. McKnight. 1988. The leucine zipper: A hypothetical structure common to a new class of DNA binding proteins. Science 240: 1759-1764.

Lane, T., C. Ibanez, A. Garcia, T. Graf, and J. Lipsick. 1990. Transformation by $\mathrm{v}$-myb correlates with trans-activation of gene expression. Mol. Cell. Biol. 10: 2591-2598

Ludwig, S.R., L.F. Habera, S.L. Dellaporta, and S.R. Wessler. 1989. $L c$, a member of the maize $R$ gene family responsible for tissue-specific anthocyanin production, encodes a protein similar to transcriptional activators and contains the myc-homology region. Proc. Natl. Acad. Sci. 86: 70927096.

Lüscher, B., E. Christenson, D.W. Litchfield, E.G. Krebs, and R.N. Eisenman. 1990. Myb DNA binding inhibited by phosphorylation at a site deleted during onccogenic activation. Nature 344: 517-522.

Majello, B., L.C. Kenyon, and R. Dalla-Favera. 1986. Human c-myb proto-oncogene: Nucleotide sequence of cDNA and 
organization of the genomic locus. Proc. Natl. Acad. Sci. 83: 9636-9640.

McClinton, D., J. Stafford, L. Brents, T.P. Bender, and W.M. Kuehl. 1990. Differentiation of mouse erythroleukemia cells is blocked by late up-regulation of a c-myb transgene. Mol. Cell. Biol. 10: 705-710.

McMahon, J., K.M. Howe, and R.J. Watson. 1988. The induction of Friend erythroleukaemia differentiation is markedly affected by expression of a transfected c-myb cDNA. Oncogene 3: 717-720.

Mitchell, P.J. and R. Tijan. 1989. Transcriptional regulation in mammalian cells by sequence-specific DNA binding proteins. Science 245: 371-378.

Mizuguchi, G., H. Nakagoshi, T. Nagase, N. Nomura, T. Date, Y. Ueno, and S. Ishii. 1990. DNA binding activity and transcriptional activator function of the human B-myb protein compared with c-Myb. J. Biol. Chem. 265: 9280-9284.

Moelling, K., E. Pfaff, H. Beug, P. Beiming, T. Bunte, H.E. Schaller, and T. Graf. 1985. DNA-binding activity is associated with purified Myb proteins from AMV and E26 viruses and is temperature-sensitive for E26 ts mutants. Cell 40: $983-990$

Moscovici, C. and L. Gazzolo. 1982. Transformation of hemopoietic cells with avian leukemia viruses. Adv. Viral Oncol. 1: $83-106$.

Ness, S.A., H. Beug, and T. Graf. 1987. v-myb dominance over $\mathrm{v}-\mathrm{myc}$ in doubly transformed chick myelomonocytic cells. Cell 51: 41-50.

Ness, S.A., A. Marknell, and T. Graf. 1989. The v-myb oncogene product binds to and activates the promyelocyte-specific mim-1 gene. Cell 59: 1115-1125.

Nishina, Y., H. Nakagoshi, F. Imamoto, T.J. Gonda, and S. Ishii. 1989. Trans-activation by the c-myb proto-oncogene. Nucleic Acids Res. 17: 107-117.

Nomura, N., M. Takahashi, M. Matsui, S. Ishii, T. Date, S. Sasamoto, and R. Ishizaki. 1988. Isolation of human cDNA clones of myb-related genes, A-myb and B-myb. Nucleic Acids Res. 16: 11075-11089.

Paz-Ares, J., D. Ghosal, U. Wienand, P.A. Peterson, and H. Saedler. 1987. The regulatory $c 1$ locus of Zea mays encodes a protein with homology to myb proto-oncogene products and with structural similarities to transcriptional activators. $E M B O$ /. 6: 3553-3558.

Peters, C.W.B., A.E. Sippel, M. Vingron, and K.H. Klempnauer. 1987. Drosophila and vertebrate myb proteins share two conserved regions, one of which functions as a DNAbinding domain. EMBO /. 6: 3085-3090.

Pizer, E. and E.H. Humphries. 1989. RAV-1 insertional mutagenesis: Disruption of the c-myb locus and development of avian B-cell lymphomas. I. Virol. 63: 1630-1640.

Ptashne, M. 1988. How eukaryotic transcriptional activators work. Nature 335: 683-689.

Radke, K., H. Beug, S. Kornfeld, and T. Graf. 1982. Transformation of both erythroid and myeloid cells by E26, an avian leukemia virus that contains the myb gene. Cell 31: 643653.

Ramsay, R.G., S. Ishii, Y. Nishina, G. Soe, and T.J. Gonda. 1989. Characterization of alternate and truncated forms of murine c-myb proteins. Oncogene Res. 4: 259-269.

Rosson, D. and E.P. Reddy. 1986. Nucleotide sequence of chicken c-myb complementary DNA and implications for myb oncogene activation. Nature 319: 604-606.

Rosson, D., D. Dugan, and E.P. Reddy. 1987. Aberrant splicing events that are induced by proviral integration: Implications for myb oncogene activation. Proc. Natl. Acad. Sci. 84: $3171-3175$.
Rushlow, K.E., J.A. Lautenberger, T.S. Papas, M.A. Baluda, B. Perbal, J.G. Chirirkhian, and E.P. Reddy. 1982. Nucleotide sequence of the transforming gene of avian myeloblastosis virus. Science 216: 1421-1423.

Sakura, H., C. Kanei-Ishii, T. Nagase, H. Nakagoshi, and T.J. Gonda. 1989. Delineation of three functional domains of the transcriptional activator encoded by the c-myb proto-oncogene. Proc. Natl. Acad. Sci. 86: 5758-5762.

Shen-Ong, G.L.C. 1987. Alternative internal splicing in c-myb RNAs occurs commonly in normal and tumor cells. EMBO I. 6: 4035-4039.

1990. The myb oncogene. Biochem. Biophys. Acta 1032: $39-52$.

Shen-Ong, G.L.C., M. Potter, J.F. Mushinski, S. Lavu, and E.P. Reddy. 1984. Activation of the c-myb locus by viral insertional mutagenesis in plasmacytoid lymphosarcomas. Science 226: $1077-1080$.

Shen-Ong, G.L.C., H.C. Morse, M. Potter, and J.F. Mushinski. 1986. Two modes of $c-m y b$ activation in virus-induced mouse myeloid tumors. Mol. Cell. Biol. 6: 380-392.

Shen-Ong, G.L.C., B. Lüscher, and R.N. Eisenman. 1989. A second $c-m y b$ protein is translated from an alternatively spliced mRNA expressed in normal and $5^{\prime}$-disrupted myb loci. Mol. Cell. Biol. 9: 5456-5463.

Shen-Ong, G.L.C., R.M. Skurla, J.D. Owens, and J.F. Mushinski. 1990. Alternative splicing of RNAs transcribed from the human c-myb gene. Mol. Cell. Biol. 10: 27152722.

Stern, S., M. Tanaka, and W. Herr. 1989. The oct-1 homoeodomain directs formation of a multiprotein-DNA complex with the HSV transactivator VP16. Nature 341: 624-630.

Thiele, C.J., P.S. Cohen, and M.A. Israel. 1988. Regulation of c-myb expression in human neuroblastoma cell during retinoic acid-induced differentiation. Mol. Cell. Biol. 8: 16771683.

Thompson, C.B., P.B. Chaloner, P.E. Neiman, and M. Groudine. 1986. Expression of the c-myb proto-oncogene during cellular proliferation. Nature 319: 374-380.

Tice-Baldwin, K., G.R. Fink, and K.T. Arndt. 1989. BASl has an Myb motif and activates HIS4 transcription only in combination with BAS2. Science 246: 931-935.

Todokoro, K., R.J. Watson, H. Higo, H. Amanuma, S. Kuramochi, H. Yanagisawa, and Y. Ikawa. 1988. Down-regulation of c-myb gene expression is a prerequisite for erythropoietin-induced erythroid differentiation. Proc. Natl. Acad. Sci. 85: 8900-8904.

Weber, B.L., E.H. Westin, and M.F. Clarke. 1990. Differentiation of mouse erythroleukemia cells enhanced by alternatively spliced c-myb mRNA. Science 249: 1291-1293.

Weinstein, Y., J.N. Ihle, S. Lavu, and E.P. Reddy. 1986. Truncation of the $c-m y b$ gene by a retroviral integration in an interleukin 3-dependent myeloid leukemia cell line. Proc. Nat1. Acad. Sci. 83: 5010-5014.

Weinstein, Y., J.L. Cleveland, D.S. Askew, U.R. Rapp, and J.N. Ihle. 1987. Insertion and truncation of c-myb by murine leukemia virus in a myeloid cell line derived from cultures of normal hematopoietic cells. I. Virol. 61: 2339-2343.

Westin, E.H., R.C. Gallo, S.K. Arya, A. Eva, L.M. Souza, M.A Baluda, S.A. Aaronson, and F. Wong-Staal. 1982. Differential expression of the amv gene in human hematopoietic cells. Proc. Natl. Acad. Sci. 79: 2194-2198.

Weston, K. and J.M. Bishop. 1989. Transcriptional activation by the v-myb oncogene and its cellular progenitor, c-myb. Cell 58: $85-93$. 


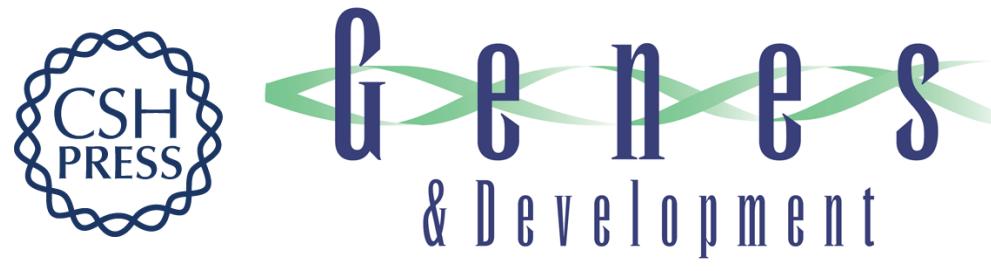

\section{New light on Myc and Myb. Part II. Myb.}

$\mathrm{B}$ Lüscher and R N Eisenman

Genes Dev. 1990, 4:

Access the most recent version at doi:10.1101/gad.4.12b.2235

References This article cites 74 articles, 36 of which can be accessed free at: http://genesdev.cshlp.org/content/4/12b/2235.full.htmI\#ref-list-1

License

Email Alerting

Receive free email alerts when new articles cite this article - sign up in the box at the top Service right corner of the article or click here.

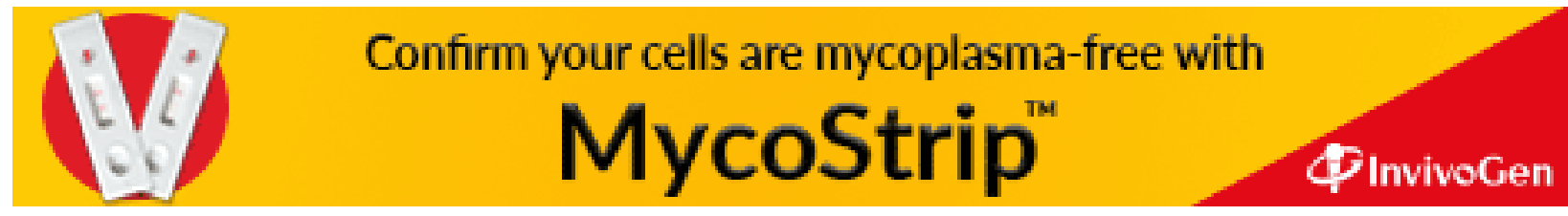

